Factor XII deficiency inhibits fibrinolysis and therefore can lead to thromboembolic complications. ${ }^{5}$ Patients with isolated factor XII deficiency have a high rate of venous thromboembolism and arterial thrombosis, leading to life threatening complications such as pulmonary embolism and myocardial infarction. ${ }^{6}$ In addition, surgical trauma and immobilization increase the risk of thromboembolic complications. This necessitates the use of thromboprophylaxis perioperatively (mechanical and pharmacological) and early aggressive mobilization postoperatively. ${ }^{7}$ We used IPCD intraoperatively and in the postoperative period, low molecular weight heparin, early mobilization, and daily screening for DVT was done in addition to continued use of IPCD.

In conclusion, patients with factor XII deficiency are at high risk of thromboembolism for which vigilant monitoring and measures for thromboprophylaxis should be undertaken perioperatively. The risk of bleeding, although present, is not so alarming. The prophylactic correction of prolonged aPTT should be given a second thought.

Conflict of Interest

None declared.

\section{References}

1 Kessler C, Coagulation factor deficiencies. In: Goldman L, ed. Cecil Textbook of Medicine. Twenty-first edition. Philadelphia, USA: Saunders Company; 2000 1004-1012

2 Halbmayer WM, Haushofer A, Schön R, et al. The prevalence of moderate and severe FXII (Hageman factor) deficiency among the normal population: evaluation of the incidence of FXII deficiency among 300 healthy blood donors. Thromb Haemost 1994;71(1):68-72

3 Barbosa ACN, Montalvão SAL, Barbosa KGN, et al. Prolonged APTT of unknown etiology: a systematic evaluation of causes and laboratory resource use in an outpatient hemostasis academic unit. Res Pract Thromb Haemost 2019;3(4):749-757

4 Dragoumanis C, Vretzakis G, Vogiatzaki T. Perioperative management of a patient with severe factor XII deficiency. Eur J Anaesthesiol 2004;21(10):829-830

5 Pauer HU, Burfeind P, Köstering H, Emons G, Hinney B. Factor XII deficiency is strongly associated with primary recurrent abortions. Fertil Steril 2003;80(3):590-594

6 Chaudhry LA, El-Sadek WYM, Chaudhry GA, Al-Atawi FE. Factor XII (Hageman Factor) deficiency: a rare harbinger of life threatening complications. Pan Afr Med J 2019;33:39

7 Bick RL, Haas S. Thromboprophylaxis and thrombosis in medical, surgical, trauma, and obstetric/gynecologic patients. Hematol Oncol Clin North Am 2003;17(1):217-258

\title{
Dilated Cardiomyopathy and Prone Position: An Anesthetic Challenge
}

\author{
Bhavna Hooda ${ }^{1}$ Saurabh Sud ${ }^{1, \oplus}$ Deepak Dwivedi ${ }^{1}$ \\ ${ }^{1}$ Department of Anaesthesia and Critical Care, Command Hospital \\ (Southern Command), Pune, Maharashtra, India \\ 2Department of Neurosurgery, Command Hospital (Southern \\ Command), Pune, Maharashtra, India
}

Sanjay K. Yadav

\begin{abstract}
Address for correspondence Saurabh Sud, MD (Anaesthesia), Department of Anaesthesia and Critical Care, Command Hospital (Southern Command), Pune 411040, Maharashtra, India (e-mail: saurabhsood1975@gmail.com).
\end{abstract}

J Neuroanaesthesiol Crit Care 2021;8:212-214.
Abstract
Keywords
- cardiac resynchronization therapy device
- dilated cardiomyopathy
- prone position

The anesthetic management of a patient with dilated cardiomyopathy (DCM) for noncardiac surgery is challenging due to associated congestive heart failure, malignant dysrhythmias, sudden cardiac arrest, implanted rhythm devices, and thromboembolism. We report successful conduct of a case of DCM on cardiac resynchronization device with Cauda equina syndrome (CES) under general anesthesia in prone position. The anesthetic concerns specific to the pathophysiology of DCM are also discussed. published online June 30,2020
DOI https://doi.org/

$10.1055 / \mathrm{s}-0040-1713726$ ISSN 2348-0548. (c) 2020. Indian Society of Neuroanaesthesiology and Critical Care. This is an open access article published by Thieme under the terms of the Creative Commons Attribution-NonDerivative-NonCommercial-License, permitting copying and reproduction so long as the original work is given appropriate credit. Contents may not be used for commercial purposes, or adapted, remixed, transformed or built upon. (https://creativecommons.org/licenses/by-nc-nd/4.0/).

Thieme Medical and Scientific Publishers Pvt. Ltd. A-12, 2nd Floor, Sector 2, Noida-201301 UP, India 


\section{Introduction}

Dilated cardiomyopathy (DCM) has an incidence of 5 to 8 per 100,000 and is characterized by decreased contractility, decreased cardiac output, and increased left ventricular (LV) filling pressures due to dilatation of one or both ventricles. ${ }^{1,2}$ There is progressive ventricular dilatation, eventually leading to congestive heartfailure, thromboembolism, valvular regurgitant lesions, malignant arrythmias, and sudden cardiac death. Patients of DCM are commonly on cardiac resynchronization therapy (CRT) device by means of biventricular pacing (CRT-P), automated internal cardioverter defibrillator (AICD), or a combo device (CRT-D with antiarrythmia function). Surgery in the prone position in DCM patients with reprogrammed CRT-P (pacing in VOO mode) further increases the chances of perioperative cardiac failure, arrhythmias, and sudden cardiac arrest. ${ }^{2}$

We report the case of a 52-year-old (body mass index [BMI]-21.4 kg/m²) hypertensive and diabetic female with DCM on Medtronic's CRT-P for severe systolic dysfunction, posted for urgent laminectomy L4 level with L4-5 discectomy and bilateral foraminotomy in prone position under general anesthesia (GA) for prolapsed intervertebral disc (PIVD) at L3-L4 and extruded caudally migrated disc at L4-L5 level with resultant Cauda equina syndrome (CES). The patient was under cardiology workup since the past 10 years for DCM. CRT-P was placed as her ejection fraction (EF) dropped to $25 \%$ 3 years ago and she became progressively limited in her physical capacity. After CRT-P implantation, she was in New York Heart Association (NYHA) class II and there was no evidence of congestive heart failure. Two-dimensional (2D) echocardiography showed LV EF of $40 \%$ with global hypokinesia, elevated left ventricle end-diastolic pressure (LVEDP) (E:A ratio 0.67), left ventricular end-diastolic dimension (LVEDD) of $65 \mathrm{~mm}$, and relative wall thickness 0.4 , all suggestive of combined LV systolic dysfunction (mild) and grade I diastolic dysfunction. The rest of the investigations were unremarkable. The patient was on losartan, aspirin, carvedilol, aldactone, and metformin. All medications were continued perioperatively; angiotensin-receptor blocker (ARB), losartan was however stopped 24 hours prior to avoid intraoperative hypotension. Preoperatively, pacemaker interrogation and resetting to VOO mode with a pacing rate of $85 \mathrm{bpm}$, availability of automated external defibrillator(AED), arterial monitoring, central venous access and preparation of vasopressor and inotrope infusions were ensured. Written informed consent was obtained and nil per oral (NPO) status was confirmed. Standard monitoring was ensured with additional right radial artery cannulation for beat-to-beat blood pressure (IBP) monitoring and central venous cannulation for the purpose of vasopressor medications. Baseline blood gas parameters were assessed for any acid base and electrolyte abnormalities. The volume assessment was done using stroke volume variation (SVV) as measured by Vigileo monitor (Vigileo; FloTrac; Edwards; Lifesciences, Irvine, CA, USA) using third-generation software (version 3.02), aiming for SVV values $<12$. Automated external defibrillator (AED) pads were placed in an anterior-posterior configuration to ensure that cardioversion if attempted would not cause pacemaker lead dislodgement/malfunction while allowing synchronized cardioversion/ defibrillation in the prone position. The right internal jugular vein (IJV) was cannulated under ultrasound guidance and infusion of noradrenalin and dobutamine were started at the rate of $0.05 \mu \mathrm{g} / \mathrm{kg} / \mathrm{min}$ and $5 \mu \mathrm{g} / \mathrm{kg} / \mathrm{min}$, respectively before induction. GA was administered with IV fentanyl $100 \mu \mathrm{g}$, titrated dose of etomidate $15 \mathrm{mg}$ and vecuronium $5 \mathrm{mg}$ IV. Postintubation heart rate (HR) and blood pressure (BP) remained within $10 \%$ of the baseline. Anesthesia was maintained with desflurane in air-oxygen mixture to allow rapid titration in order to keep hemodynamics stable. On turning the patient prone, BP dropped drastically to $80 / 48 \mathrm{~mm} \mathrm{Hg}$ from 150/96 mm Hg and cardiac rhythm deteriorated to atrial fibrillation (AF). With the AED pads in place and significant hypotension, a synchronized cardioversion with $25 \mathrm{~J}$ was attempted. The rhythm soon reverted to pacing rhythm of 85 beats per minute and infusion rates of noradrenalin and dobutamine were adjusted to keep BP and HR within $10 \%$ of the baseline. The patient's BP fluctuated a lot in first 20 to 25 minutes after making prone, and frequent adjustments in infusion rates were needed. The rest of the perioperative period was uneventful. Anticipating similar drop in hemodynamics on turning patient supine at the conclusion of surgery, vasopressor and inotrope infusions were overtitrated; intuitively, the hemodynamics stayed stable and patient was extubated fully awake. Postoperatively, the patient was monitored in the intensive care unit (ICU), and infusion of noradrenalin and dobutamine tapered off by postoperative evening. Pacing was resumed to the preoperative DDD mode with CRT-D in the ICU, and the patient was discharged after 5 days with complete recovery of neurologic function.

\section{Discussion}

Patients with DCM have a complicated pathophysiology with elevated LV filling pressures, myocardial contractile dysfunction and tendency for malignant arrythmias and sudden cardiac arrest. Additionally, these patients are precariously balanced on an inverse relationship between stroke volume and afterload. Therefore, the anesthetic goals are to maintain normovolemia, avoid increases in ventricular afterload, prevent myocardial depression, and avoid overdosage of drugs during induction as circulation time is slow in these patients. ${ }^{3}$ Further, preoperative symptomatic diastolic dysfunction is associated with a higher risk of postoperative major adverse cardiac events (MACEs), the risk being more with a grade III diastolic dysfunction. ${ }^{4}$ Commonly, practicing anesthesiologists pay more attention to the preoperative EF as a measure of LV systolic function for cardiac risk stratification, while overlooking the diastolic dysfunction, particularly heart failure with preserved ejection fraction (HFpEF). There is a strong relationship between diastolic dysfunction, HFpEF-induced LA structural remodeling and AF, emphasizing avoidance of acute changes in HR, and hemodynamic overload. Therefore, titration of anesthesia should be approached with altered pharmacodynamics at the core, employing one-third to one-half of the anesthetic dosages at induction and using cardio stable drugs, to account for the slow transit time and reduced cardiac reserve. ${ }^{3,5}$ 
Literature research shows that infusion of noradrenalin and dobutamine before induction is effective in countering the depressive effect of anesthetic drugs. ${ }^{6}$ Further, cardiostable and short-acting drugs such as etomidate, fentanyl, and vecuronium are employed as part of anesthetic regime. Noninvasive continuous cardiac output monitoring is used to evaluate the ventricular performance in response to fluid therapy, inotropes, and prone positioning. ${ }^{7}$ Prone position leads to increased intrathoracic pressure reducing venous return, and decrease in cardiac output (CO) and cardiac index (CI), which is exaggerated in DCM patients.

A noteworthy point with regard to pacing in these patients: preoperative conversion to asynchronous mode of CRT-P is necessary, in order to prevent pacemaker inhibition by electromechanical interference and use of bipolar cautery and also prevent pacemaker malfunction. For AICD, since these patients are not pacemaker-dependent, simple deactivation of the ICD intraoperatively may suffice. ${ }^{8,9}$ Additionally, AED pads should be placed before induction in the anterior-posterior configuration, so that the cardioversion/defibrillation current would not cross the pacemaker path.

\section{Conclusion}

Anesthetic management of patients with DCM on CRT device poses unique challenge for the anesthesiologist, with strong likelihood of catastrophic hemodynamic perturbations, dysrhythmias, and even sudden cardiac arrest. Particularly in surgery in prone position with limited access to the patient in the event of a catastrophe, meticulous planning, vigilant monitoring, adequate preparation with anterior-posterior configuration of transthoracic pads, judicious use of pharmacological agents, and tailor-made anesthetic regime, can lead to a favorable outcome.

\section{Conflict of Interest}

None declared.

\section{References}

1 Kaur H, Khetarpal R, Aggarwal S. Dilated cardiomyopathy: an anaesthetic challenge. J Clin Diagn Res 2013;7(6):1174-1176

2 Pradhan R, Vaidya PR, Shrestha RR, Parajuli S, Joshi HR, Shah BL. Dilated cardiomyopathy and anesthesia in prone position: a case report. Postgraduate Medical Journal of NAMS. 2016;16:42-45

3 Raj R, Kumar M, Batra M. Anaesthetic management of a case of dilated cardiomyopathy for emergency appendectomy. Anesth Essays Res 2014;8(1):105-107

4 Zhou Y, Liu L, Cheng T, et al. Grade 3 echocardiographic diastolic dysfunction is associated with increased risk of major adverse cardiovascular events after surgery: a retrospective cohort study. Anesth Analg 2019;129(3):651-658

5 Godfrey GEP, Peck MJE. Diastolic dysfunction in anaesthesia and critical care. BJA Educ 2016;16(9):287-291

6 Davies MR, Cousins J. Cardiomyopathy and anaesthesia. Contin Educ Anaesth Crit Care Pain 2009;9(6):189-193

7 Alhashemi JA, Cecconi M, Hofer CK. Cardiac output monitoring: an integrative perspective. Crit Care 2011;15(2):214

8 Stone ME, Salter B, Fischer A. Perioperative management of patients with cardiac implantable electronic devices. $\mathrm{Br} \mathrm{J}$ Anaesth 2011;107(Suppl 1):i16-i26

9 Practice Advisory for the Perioperative Management of Patients with Cardiac Implantable Electronic Devices: Pacemakers and Implantable Cardioverter-Defibrillators 2020: An Updated Report by the American Society of Anesthesiologists Task Force on Perioperative Management of Patients with Cardiac Implantable Electronic Devices*. Anesthesiology 2020;132(2): 225-252

\title{
Management of a Difficult Airway Scenario in a Case of Hurler's Syndrome with a D-Blade Video Laryngoscope
}

\author{
Keta D. Thakkar ${ }^{1, \odot}$ Ajay P. Hrishi ${ }^{1, \odot} \quad$ Manikandan Sethuraman ${ }^{1, \odot} \quad$ Smita Vimala ${ }^{1, \odot}$ \\ ${ }^{1}$ Department of Anaesthesiology, Division of Neuroanesthesia, \\ Sree Chitra Tirunal Institute for Medical Sciences and Technology, \\ Thiruvananthapuram, Kerala, India \\ Address for correspondence Ajay P. Hrishi, MD, DM, Department \\ of Anaesthesiology, Division of Neuroanesthesia, Surgical block, \\ Sree Chitra Tirunal Institute for Medical Sciences and Technology, \\ Trivandrum, Kerala 695011, India (e-mail: drajay@sctimst.ac.in).
}

J Neuroanaesthesiol Crit Care 2021;8:214-216.

published online

August 10, 2020
DOI https://doi.org/

$10.1055 / \mathrm{s}-0040-1714451$

ISSN 2348-0548. (c) 2020. Indian Society of Neuroanaesthesiology and Critical Care. This is an open access article published by Thieme under the terms of the Creative Commons Attribution-NonDerivative-NonCommercial-License, permitting copying and reproduction so long as the original work is given appropriate credit. Contents may not be used for commercial purposes, or adapted, remixed, transformed or built upon. (https://creativecommons.org/licenses/by-nc-nd/4.0/).

Thieme Medical and Scientific Publishers Pvt. Ltd. A-12, 2nd Floor, Sector 2, Noida-201301 UP, India 